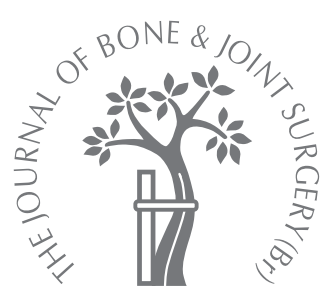

R. T. Steffen, H. P. Pandit, J. Palan, D. J. Beard, R. Gundle, P. McLardy-Smith, D. W. Murray, H. S. Gill

\section{From Nuffield} Orthopaedic Centre, Oxford, England

\title{
The five-year results of the Birmingham Hip Resurfacing arthroplasty
}

\author{
AN INDEPENDENT SERIES
}

Few independent studies have reported the outcome of resurfacing arthroplasty of the hip. The aim of this study was to report the five-year clinical outcome and seven-year survival of an independent series.

A total of 610 Birmingham Hip Resurfacing arthroplasties were performed in $\mathbf{5 3 2}$ patients with a mean age of 51.8 years (16.5 to 81.6). They were followed for between two and eight years; 107 patients (120 hips) had been followed up for more than five years. Two patients were lost to follow-up. At a minimum of five years' follow-up, 79 of 85 hips (93\%) had an excellent or good outcome according to the Harris hip score. The mean Oxford hip score was $\mathbf{1 6 . 1}$ points (SD 7.7) and the mean University of California Los Angeles activity score was 6.6 points (SD 1.9). There were no patients with definite radiological evidence of loosening or of narrowing of the femoral neck exceeding $10 \%$ of its width. There were 23 revisions $(3.8 \%)$, giving an overall survival of $95 \%$ (95\% confidence interval 85.3 to 99.2$)$ at seven years. Fractured neck of femur in 12 hips was the most common indication for revision, followed by aseptic loosening in four. In three hips (three patients) $(0.5 \%)$, failure was possibly related to metal debris.

Considering that these patients are young and active these results are good, and support the use of resurfacing. Further study is needed to address the early failures, particularly those related to fracture and metal debris.

In. T. Steffen, MRCS, Clinical Research Fellow - H. P. Pandit, FRCS(Orth), Clinical Research Fellow I- J. Palan, MRCS, Clinical Research Fellow

D. J. Beard, DPhil, University Research Lecturer

II. Gundle, FRCS, Consultant Orthopaedic Surgeon

P. McLardy-Smith, FRCS Consultant Orthopaedic Surgeon

D. W. Murray, FRCS(Orth)

Professor of Orthopaedic

Surgery

H. S. Gill, DPhil, University

Lecturer in Orthopaedic

Engineering

Nuffield Department of

Orthopaedic Surgery

University of Oxford, Nuffield

Orthopaedic Centre, Oxford

OX3 7LD, UK.

Correspondence should be sent to Dr H. S. Gill; e-mail:

richie.gill@ndos.ox.ac.uk

(C)2008 British Editorial Society of Bone and Joint Surgery doi:10.1302/0301-620X.90B4. $19648 \$ 2.00$

$J$ Bone Joint Surg $[\mathrm{Br}]$ 2008;90-B:436-41.

Received 8 May 2007;

Accepted after revision 19

December 2007
During 2004 almost $46 \%$ of patients (1585 of 3471) under the age of 55 years undergoing primary hip replacement in the United Kingdom received a resurfacing procedure, ${ }^{1}$ the most commonly-used device being the Birmingham Hip Resurfacing arthroplasty (BHR, Smith \& Nephew-MMT, Birmingham, United Kingdom). Data from the Australian National Joint Replacement Registry show that the BHR was the second most commonly-used implant with a cemented femoral component for hip replacement in Australia during 2004. ${ }^{2}$ Since its introduction in 1997, more than 60000 have been implanted. ${ }^{3}$ Most studies on the BHR have been from the centre responsible for its development ${ }^{4-7}$ and show excellent results, particularly in young patients with osteoarthritis $(\mathrm{OA}){ }^{4} \quad$ Few independent series have reported ${ }^{8}$ and most have either described small numbers ${ }^{9,10}$ or follow-up periods of less than five years. ${ }^{11-13}$ The purpose of this study was to perform a survival analysis of a large series of BHRs implanted at an independent hospital with a minimum follow-up of two years and a comprehensive review of patients five years after surgery.

\section{Patients and Methods}

A total of 610 consecutive BHRs were implanted between June 1999 and April 2006, of which 120 (107 patients) have been followed up for more than five years. The latter were termed the five-year group. The entire group were under the care of seven consultant orthopaedic surgeons who supervised 30 surgical trainees during this time; 497 BHRs were performed by consultants and 113 by trainees. During the same period approximately 3300 total hip replacements were performed.

The entire group involved 532 patients, 316 men $(59 \%)$ and 216 women (41\%). The mean age at the time of surgery was 51.8 years $(16.5$ to 81.6 ). There were 78 bilateral cases, of which 21 were performed simultaneously. The most common diagnosis was primary OA (85\%, 519 hips), followed by OA secondary to dysplasia (9.3\%, 57 hips) (Table I).

The extended posterior approach was used in all cases, following the technique of McMinn et al. ${ }^{5}$ Either CMW3 cement (DePuy Ltd, Blackpool, United Kingdom) with gentamicin or Simplex cement (Stryker, Newbury, 
Table I. Distribution of pre-operative diagnoses. 'Other' includes osteoarthritis (OA) secondary to slipped upper femoral epiphysis, Perthes' disease and septic arthritis

\begin{tabular}{|c|c|c|c|c|c|c|}
\hline & Number of hips & Age (yrs) & Primary OA (\%) & Dysplasia (\%) & AVN* $(\%)$ & Other $(\%)$ \\
\hline Entire cohort & 610 & 51.8 (16.5 to 81.6$)$ & $85 \quad(519)$ & $9.3(57)$ & 3 (18) & $2.7(16)$ \\
\hline$<50$ yrs & 231 & 41.7 (16.5 to 49.9 ) & $77.5(179)$ & $13 \quad(30)$ & $4.8(11)$ & $4.8(11)$ \\
\hline$>50$ yrs & 379 & 58.1 (50.0 to 81.6$)$ & $90 \quad(340)$ & $7.1(27)$ & $1.9(7)$ & $1.3(5)$ \\
\hline Five-year group & 120 & 50.5 (26.0 to 70.0$)$ & $91.7(110)$ & $1.7(2)$ & $5.8(7)$ & $0.8(1)$ \\
\hline
\end{tabular}

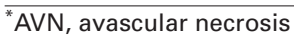

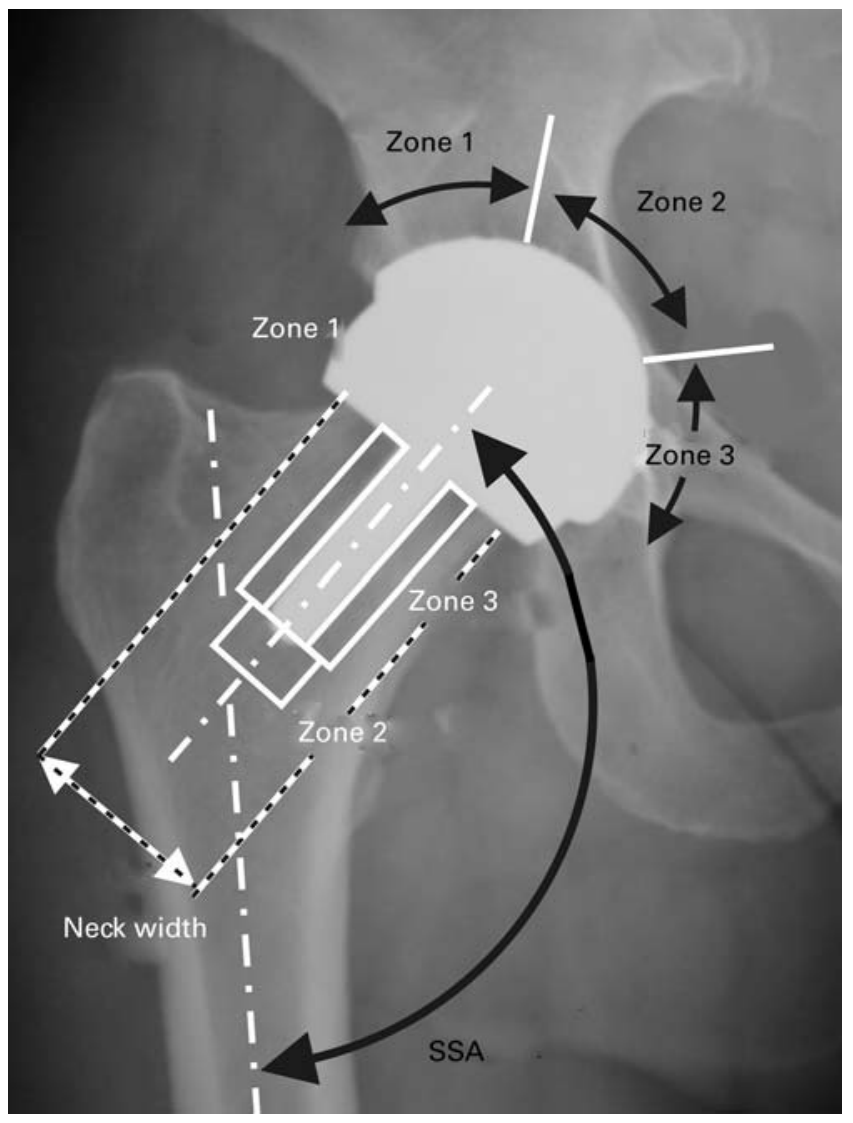

Fig. 1

Definition of radiological zones, stem-shaft angle (SSA) and neck width.

United Kingdom) with tobramycin was used to fix the femoral component.

In the five-year group there were 75 men and 32 women, with a mean age at the time of surgery of 50.5 years $(26$ to 70). The diagnosis was primary OA in 110 hips, avascular necrosis (AVN) in seven, and secondary OA in three (developmental dysplasia in two and septic arthritis in one). There were 13 bilateral cases, of which 12 were performed simultaneously.

The Oxford hip score (OHS) ${ }^{14}$ and University of California Los Angeles (UCLA) activity score ${ }^{15}$ questionnaires were sent to all patients, and all those in the five-year group were invited to attend for review. The OHS has a maximum of 60 points (worst outcome) and a minimum of 12 points (best outcome), and the UCLA score has a minimum of one point (wholly inactive) and a maximum of ten points (undertaking regular impact sports). A sub-analysis was performed dividing the hips based on the age of the patients into young $(<50$ years, $\mathrm{n}=231)$ and older $(\geq 50$ years, $\mathrm{n}=379$ ) age groups. The distribution of pre-operative diagnoses was different in these two groups. Primary OA accounted for $77.5 \%$ (179) of the young group and $90 \%$ (340) of the older group (Table I), whereas OA secondary to dysplasia accounted for $13 \%$ (30) of the young group and $7.1 \%$ (27) of the older group. The distributions of the groupings of diagnoses, primary OA, OA secondary to dysplasia and all others, were compared between the young and older groups using the chi-squared test.

At review for the five-year group, patients were examined radiologically and clinically. The position of the femoral component was assessed radiologically by measuring the stem-shaft angle, and radiolucent lines around the femoral ${ }^{16}$ and acetabular components were recorded. The definition of the zones is given in Figure 1. The incidence and amount of heterotopic ossification ${ }^{17}$ was assessed. The amount of narrowing of the femoral neck ${ }^{5}$ was determined (Fig. 1), with the magnification corrected using the known size of the femoral component.

The patients were clinically assessed with the Harris hip score (HHS), ${ }^{18}$ which ranges from zero points (worst outcome) to 100 points (best outcome).

Implant survival for the entire cohort was established, with revision as the final endpoint as described by Murray, Carr and Bulstrode, ${ }^{19}$ and the Rothman equation was used to obtain the $95 \%$ confidence limits. Survival was separately established for the entire cohort divided into young and older groups, and the five-year group. For those who could not attend the clinic, survival was established by telephone interview and GP records. Statistical analyses were performed using SPSS (version 12, SPSS Inc., Chicago, Illinois).

\section{Results}

For the entire cohort of 532 patients (610 hips), only two were lost to follow-up. These patients are included in the results as we had their size usage data. The mean follow-up 
Table II. Life table of all 610 hips

\begin{tabular}{|c|c|c|c|c|c|c|c|c|c|}
\hline Year & $\begin{array}{l}\text { Number at } \\
\text { start }\end{array}$ & Failures & Withrawn & $\begin{array}{l}\text { Loss to } \\
\text { follow-up }\end{array}$ & $\begin{array}{l}\text { Number at } \\
\text { risk }\end{array}$ & $\begin{array}{l}\text { Annual } \\
\text { failure rate } \\
(\%)\end{array}$ & $\begin{array}{l}\text { Annual } \\
\text { success } \\
\text { rate }(\%)\end{array}$ & $\begin{array}{l}\text { Accumulated } \\
\text { survival (\%) }\end{array}$ & $\begin{array}{l}95 \% \text { confidence } \\
\text { interval }\end{array}$ \\
\hline 0 to 1 & 610 & 13 & 14 & 2 & 602.0 & 2.2 & 97.8 & 97.8 & 96.3 to 98.7 \\
\hline 1 to 2 & 581 & 2 & 29 & 0 & 566.5 & 0.4 & 99.6 & 97.5 & 95.9 to 98.5 \\
\hline 2 to 3 & 550 & 3 & 101 & 0 & 499.5 & 0.6 & 99.4 & 96.9 & 95.0 to 98.1 \\
\hline 3 to 4 & 446 & 4 & 141 & 0 & 375.5 & 1.1 & 98.9 & 95.8 & 93.3 to 97.4 \\
\hline 4 to 5 & 302 & 0 & 123 & 0 & 240.5 & 0.0 & 100.0 & 95.8 & 92.4 to 97.8 \\
\hline 5 to 6 & 179 & 1 & 99 & 0 & 129.5 & 0.8 & 99.2 & 95.1 & 89.8 to 97.9 \\
\hline 6 to 7 & 79 & 0 & 55 & 0 & 51.5 & 0.0 & 100.0 & 95.1 & 85.3 to 99.2 \\
\hline 7 to 8 & 24 & 0 & 24 & 0 & 12.0 & 0.0 & 100.0 & 95.1 & 67.9 to 108.2 \\
\hline
\end{tabular}

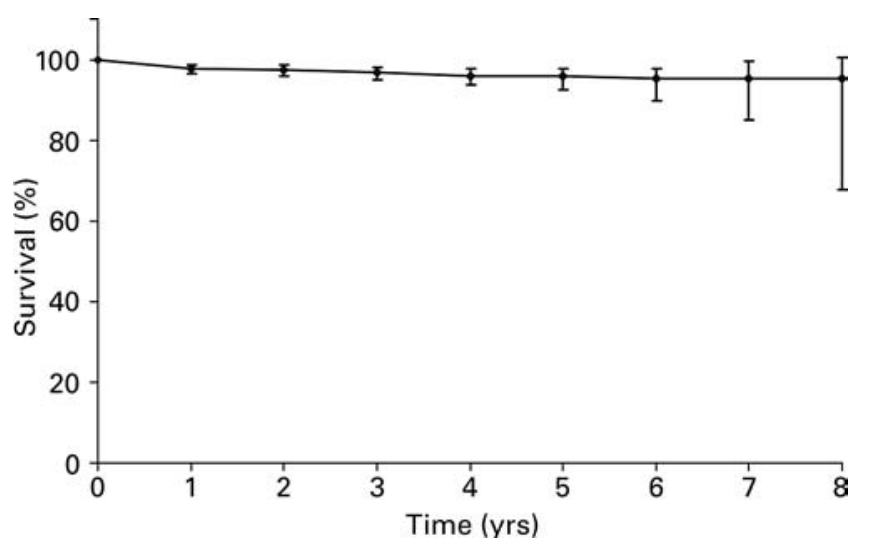

Fig. 2

Survival curve for entire cohort of Birmingham Hip Resurfacings.

was 4.2 years (2.0 to 7.6). The OHS and UCLA scores were obtained for 507 (83\%) hips. Survival was established for all but the two patients lost to follow-up. The mean OHS was 16.1 points (SD 7.7). The mean UCLA activity score was 6.6 points (SD 1.9). The most commonly-used femoral components had a diameter of $46 \mathrm{~mm}$ in 185 hips (30\%), $50 \mathrm{~mm}$ in $168(28 \%)$ and $54 \mathrm{~mm}$ in 159 (26\%), with a range from $38 \mathrm{~mm}$ to $58 \mathrm{~mm}$. The overall median head size was $50 \mathrm{~mm}$.

In the sub-analysis comparing the young and the older patients, scores were obtained for $173(75 \%)$ of the young and $328(87 \%)$ of the older patients. The mean OHS was significantly higher (Mann-Whitney U test, $\mathrm{p}=0.019$ ) for the young patients (17.7 points, SD 9.7), than for the older patients (15.2 points, SD 6.2). The mean UCLA activity scores were similar between the two groups with 6.4 points (SD 2.2) for the young and 6.8 (SD 1.7) for the older patients. The distribution of the three diagnostic groups (OA, dysplasia and other) was statistically significantly different between the young and older patients (chi-squared test, $\mathrm{p}<0.001)$. There were also statistically significant differences between the median ages at the time of surgery of the three diagnostic groups (Kruskal-Wallis, $\mathrm{p}<0.001$ ); the median age of patients with primary OA was 54 years (19 to 81.6 ), that of patients with OA secondary to dysplasia was 49.6 years (19.2 to 60) and that for those with other diagnoses was 42.6 years (20.2 to 63.1$)$.

There were a total of 23 revisions $(3.8 \%$ ) (nine in males $(39 \%), 14$ in females $(61 \%))$, giving an overall survival of $95 \%$ at seven years $(95 \%$ confidence interval (CI) 85.3 to 99.2; Table II, Fig. 2). If the two cases lost to follow-up were included as failures, survival was $94 \%$ (95\% CI 84 to 98). A total of 13 revisions were undertaken during the first year after implantation (Fig. 3). The most common cause of failure was fractured neck of femur in 12 hips, two of which occurred intra-operatively. Failure was caused by aseptic loosening in four hips loosening of the acetabular component in three and of the femoral component in one. Unexplained pain, infection and recurrent dislocation each accounted for two cases of revision. Impingement was the reason for the remaining revision. The older age group had a higher survival of $96 \%(95 \%$ CI 79 to 100.2$)$ at seven years, compared with $94 \%$ (95\% CI 76 to 100.4 ) at eight years for the younger group.

For the revision cases, the primary diagnoses were primary OA for 17 hips (74\%), OA secondary to dysplasia in five $(22 \%)$, and in the remaining hip $(4 \%)$ it was unclear whether the diagnosis was primary OA or inflammatory arthritis. The mean age of the patients who underwent revision at primary surgery was 49.5 years (19.5 to 62); their mean post-operative stem-shaft angle was $138^{\circ}$ (SD 7.8). Two of the patients who underwent revision had large acetabular cysts and two had large femoral cysts. The most commonly-used femoral component in patients undergoing revision had a diameter of $46 \mathrm{~mm}$ in nine hips (39\%), $50 \mathrm{~mm}$ in five $(22 \%), 42 \mathrm{~mm}$ in four $(17 \%)$ and $54 \mathrm{~mm}$ in four $(17 \%)$, with a range between $38 \mathrm{~mm}$ and $54 \mathrm{~mm}$. The median head size was $46 \mathrm{~mm}$.

For the five-year group, the mean follow-up was 5.3 years (5 to 7.6$)$. A total of 85 hips $(71 \%)$ were reviewed radiologically and clinically. The remaining 35 hips in 30 patients were assessed by post or telephone. The mean stem-shaft angle was $139^{\circ}$ (SD 7.5). A stem-shaft angle between $130^{\circ}$ and $150^{\circ}$ was documented for 69 hips (81\%) in the five-year group. There were $11(13 \%)$ in varus (stem- 


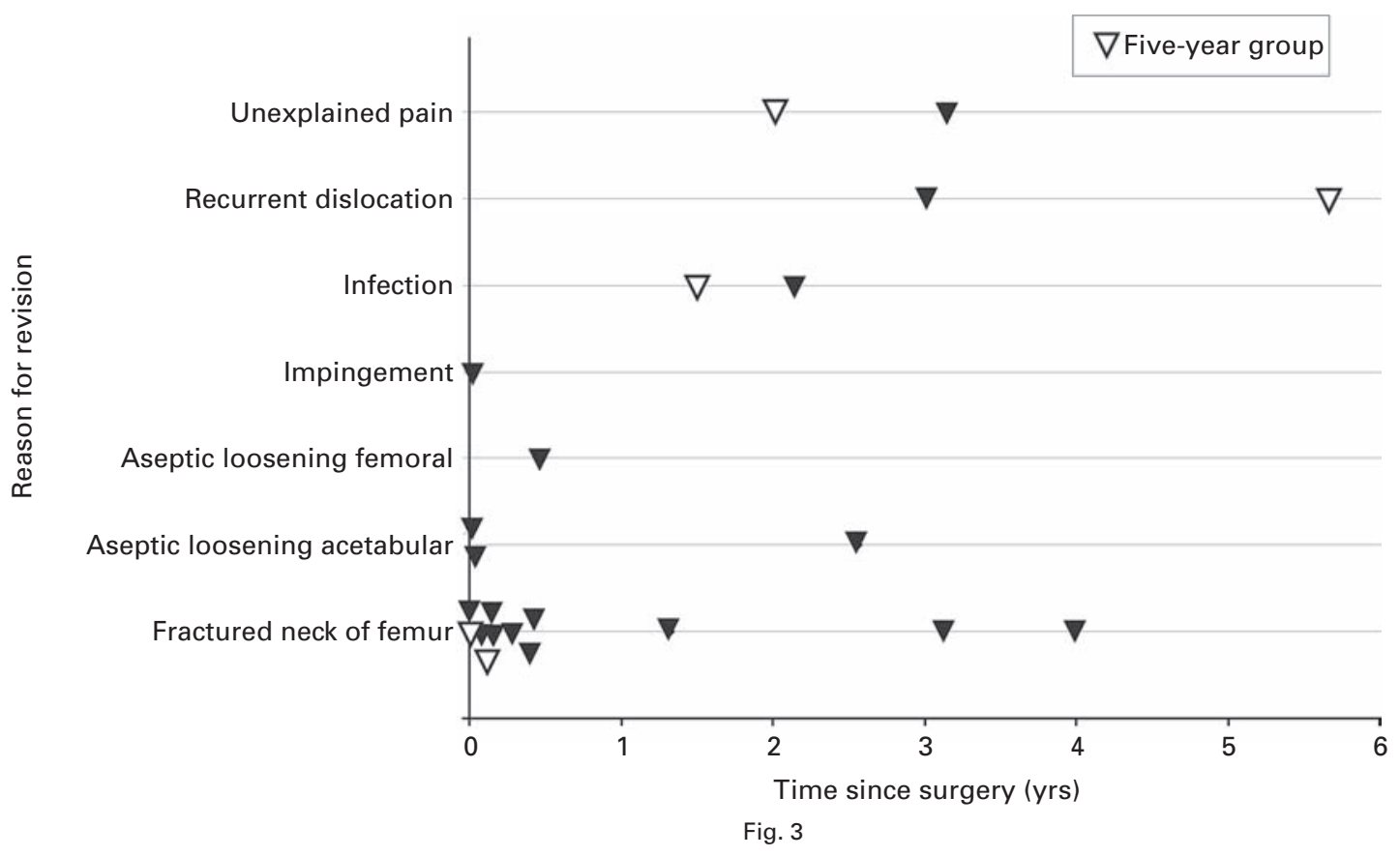

Graph showing failure type and time of occurrence.

shaft angle $<130^{\circ}$ ) and five $(6 \%)$ in valgus (stem-shaft angle $>150^{\circ}$ ).

The clinical scores for this group were similar to those of the whole cohort, the mean OHS was 16.4 points (SD 6.8), and the mean UCLA activity score was 6.7 points (SD 1.8 ). The mean HHS was 93.1 points (SD 12.7); 70 hips (82\%) had an excellent clinical outcome according to the HHS criteria (90 to 100$)$, nine $(11 \%$ ) had a good outcome (80 to $90)$, three $(3.5 \%)$ had a fair outcome $(70$ to 80$)$ and three $(3.5 \%)$ had a poor outcome (score $>70)$. The mean hip flexion was $105^{\circ}\left(40^{\circ}\right.$ to $\left.140^{\circ}\right)$. We found no relationship between outcome and component position or patient characteristics such as gender and body mass index. There were five revisions ( $4 \%$ ), two for fractured neck of femur, one for unexplained pain, one for infection and one for dislocation.

From the 85 radiological examinations available, radiolucency around the acetabular component was seen in seven cases $(8.2 \%)$, in five of which $(6 \%)$ this was limited to zone 2 (Fig. 1). There was only one case of complete acetabular radiolucency. This case was the only one in which zone 1 was involved. The width of the acetabular radiolucent lines varied from $1.2 \mathrm{~mm}$ to $3.9 \mathrm{~mm}$. Radiolucencies were less common around the femoral component, with only one of $1.5 \mathrm{~mm}$ thickness, seen in zone 2 . However, a thin sclerotic line was seen in 64 hips $(75 \%)$ of which only $40(47 \%)$ were seen in zone 2 . For the remaining 24 hips, the sclerotic line was observed in all three zones and was approximately $0.5 \mathrm{~mm}$ thick.

Heterotopic ossification was seen in 26 hips (30\%) of the available radiological examinations. Most, 19 hips (22\%) were Brooker grade I, five hips $(6 \%)$ were grade II and two $(2 \%)$ grade III.

When comparing the follow-up radiographs to the postoperative films, some narrowing of the femoral neck was seen in $30 \%$. In most cases this was between $1 \mathrm{~mm}$ and $2 \mathrm{~mm}$, representing a narrowing of $<5 \%$. Further narrowing was only seen in seven hips $(8 \%)$, the amount varying between $6 \%$ and $10 \%$. In no case was there narrowing of $>10 \%$.

During the 20 revision procedures performed at our centre, a number of observations were made. The two cases revised for infection had large amounts of serous fluid present, and histology confirmed lymphocyte infiltration in the lining tissues, reminiscent of an immunological response to wear particles. The bone marrow showed areas of degeneration and osteonecrosis of cortical bone surrounding the macrophage response. In these two cases no organisms were grown. The case revised at 5.6 years for recurrent dislocation had large amounts of metallosis and massive thickening of the local soft tissues. In the case revised for unexplained pain, the components were securely-fixed. Of the cases revised for fracture, histology for the two intra-operative cases only showed evidence of a recent fracture. For the remaining fracture cases there was evidence of extensive established AVN.

There were no major medical complications.

\section{Discussion}

Our results demonstrate that with the BHR arthroplasty, implanted using the extended posterior approach, the five- 
year survival is similar to or better than the survival rates that have been reported for cemented and hybrid THRs in young patients. ${ }^{20-22}$ The overall survival at seven years was $95 \%$.

It was interesting to note that younger patients had a significantly worse outcome in terms of OHS than the older patients, and slightly worse survival. This is probably explained by the larger proportion of patients with diagnoses other than primary $\mathrm{OA}$ in the younger group. The patients with secondary OA were significantly younger at the time of surgery than those with primary OA. The OHS results for our younger patients were higher than those reported by Pollard et al, ${ }^{9}$ who recorded a mean OHS of 15.9 for young patients who underwent resurfacing arthroplasty. Their patients had a minimum of 3.5 years' followup, the mean follow-up in our study was 4.2 years. A limitation of our study is the absence of pre-operative data. The worse OHS scores for younger patients could be due to lower pre-operative values for many in this group. The overall activity levels were relatively high, indicating participation in moderate sporting activities, but the mean activity level was lower than has been reported in other studies. ${ }^{4,7,9}$

The survival in our series was lower than that reported by Daniel et $\mathrm{al}^{4}$ and by Treacy et $\mathrm{al}^{7}$ both from the design centre. Daniel et $\mathrm{al}^{4}$ described a homogeneous group of young patients with OA; our patients had a number of underlying diagnoses. Our results suggest a poorer outcome for diagnoses other than OA; this is supported by recent data from Amstutz, Antoniades and Le Duff ${ }^{23}$ showing a poor outcome for patients with dysplasia. Our survival is similar to that reported by Nishii et al, ${ }^{10}$ whose patients had a mixture of diagnoses; they reported a $96 \%$ survival at five years. Dysplasia represented $22 \%$ of our revision cases, compared with $9.3 \%$ of the overall cohort.

The patients undergoing revision had a similar mean age to the overall cohort, and in terms of the position of the components there were no noticeable differences from the well-functioning patients. Female patients represented $61 \%$ of the revision group, compared with $41 \%$ of the total cohort. The median diameter of the femoral component was smaller in the patients undergoing revision than in the whole cohort. Only four of the patients undergoing revision had large cysts. These findings indicate that females and patients with small sizes of femoral component are more at risk of revision after resurfacing; this is in agreement with Amstutz et al. ${ }^{16}$

Femoral neck fracture represents the most common indication for revision, and most fractures occurred during the first year. This agrees with previous reports, ${ }^{9,24}$ and is thought to be due to interruption of the femoral blood supply during surgery. ${ }^{26}$ It would be interesting to compare these findings for similarly-sized series performed using approaches other than the extended posterior. The most appropriate way to examine risk factors for fracture is to compare those patients who have sustained a fracture with a control group. ${ }^{26}$ Reporting risk factors without a control group will over-emphasise the involvement of any of the factors considered. Early aseptic loosening of the acetabular component is probably due to either inadequate impaction or reaming. There is a continuing need for appropriate training and recognition of the differences between the uncemented acetabular component of a resurfacing device and that of a standard total hip replacement.

The widespread appearance of sclerotic or reaction lines around the stem of the femoral component is interesting, but it is not clear what this signifies. Pollard et $\mathrm{al}^{9}$ reported femoral radiolucencies and what they termed 'the pedestal sign'. We suspect that the reaction lines are due to an alteration of the local femoral mechanics resulting from the modulus mismatch between the stem and the host bone.

A small amount of femoral neck narrowing was recorded in a third of the five-year group. This phenomenon has been reported by others. ${ }^{11,16,27}$ The amount of neck narrowing that we observed was always less than $10 \%$, and at present we do not consider it to be clinically relevant.

The findings at revision suggest that in a small number of patients there appears to be a reaction to metal. The exact mechanism of this phenomenon is unknown and warrants further investigation.

In conclusion, considering that these patients are young and active, these results are good and support the use of resurfacing. However, further study is needed to address the early failures, particularly those related to fracture and metal debris.

Although none of the authors has received or will receive benefits for personal or professional use from a commercial party related directly or indirectly to the subject of this article, benefits have been or will be received but will be directed solely to a research fund, foundation, educational institution, or other nonprofit organisation with which one or more of the authors are associated.

\section{References}

1. No authors listed. National Joint Registry for England and Wales. http://www.njrcentre.org.uk/Public/prev_annual_reports.htm (date last accessed 17 February 2008).

2. Graves SE, Davidson D, Ingerson L, et al. The Australian Orthopedic Association National Joint Replacement Registry. Med J Aust 2004;180(Suppl):31-4.

3. No authors listed. Smith and Nephew. http://www.hipresurfacing.com/patients.asp (date last accessed 17 February 2008).

4. Daniel J, Pynsent PB, McMinn DJ. Metal-on-metal resurfacing of the hip in patients under the age of 55 years with osteoarthritis. J Bone Joint Surg [Br] 2004;86-B:177-84.

5. McMinn D, Treacy R, Lin K, Pynsent P. Metal on metal surface replacement of the hip: experience of the McMinn prosthesis. Clin Orthop 1996;329(Suppl):89-98.

6. McMinn DJ, Daniel J, Pynsent PB, Pradhan C. Mini-incision resurfacing arthroplasty of hip through the posterior approach. Clin Orthop 2005;441:91-8.

7. Treacy RB, McBryde CW, Pynsent PB. Birmingham hip resurfacing arthroplasty: a minimum follow-up of five years. J Bone Joint Surg [Br] 2005;87-B:167-70.

8. Hing CB, Back DL, Bailey $\mathbf{M}$, et al. The results of primary Birmingham hip resurfacings at a mean of five years: an independent prospective review of the first 230 hips. J Bone Joint Surg [Br] 2007;89-B:1431-8.

9. Pollard TC, Baker RP, Eastaugh-Waring SJ, Bannister GC. Treatment of the young active patient with osteoarthritis of the hip: a five- to seven-year comparison of hybrid total hip arthroplasty and metal-on-metal resurfacing. J Bone Joint Surg [Br] 2006;88-B:592-600.

10. Nishii T, Sugano N, Miki H, et al. Five-year results of metal-on-metal resurfacing arthroplasty in Asian patients. J Arthroplasty 2007;22:176-83.

11. Back DL, Dalziel R, Young D, Shimmin A. Early results of primary Birmingham hip resurfacings: an independent prospective study of the first 230 hips. J Bone Joint Surg [Br] 2005;87-B:324-9.

12. DeSmet KA, Pattyn C, Verdonck R. Early results of a primary Birmingham hip resurfacing using a hybrid metal-on-metal couple. Hip Int 2002;12:158-62. 
13. Pollard TCB, Basu C, Ainsworth R, Lai W, Bannister GC. Is the Birmingham hip resurfacing worthwhile? Hip Int 2003;13:25-8.

14. Dawson J, Fitzpatrick R, Carr A, Murray D. Questionnaire on the perceptions of patients about total hip replacement. J Bone Joint Surg [Br]1996;78-B:185-90.

15. Zahiri CA, Schmalzried TP, Szuszczewicz ES, Amstutz HC. Assessing activity in joint replacement patients. J Arthroplasty 1998;13:890-5.

16. Amstutz HC, Beaulé PE, Dorey FJ, et al. Metal-on-metal hybrid surface arthroplasty: two to six-year follow-up study. J Bone Joint Surg [Am]2004;86-A:28-39.

17. Brooker AF, Bowerman JW, Robinson RA, Riley LH Jr. Ectopic ossification following total hip replacement: incidence and a method of classification. J Bone Joint Surg [Am] 1973;55-A:1629-32.

18. Harris WH. Traumatic arthritis of the hip after dislocation and acetabular fractures: treatment by mold arthroplasty: an end-result study using a new method of result evaluation. J Bone Joint Surg [Am] 1969;51-A:737-55

19. Murray DW, Carr AJ, Bulstrode C. Survival analysis of joint replacements. J Bone Joint Surg [Br] 1993;75-B:697-704.

20. White SH. The fate of cemented total hip arthroplasty in young patients. Clin Orthop 1988:231:485-91.
21. Sporer SM, Callaghan JJ, Olejniczak JP, Goetz DD, Johnstone RC. Hybrid total hip arthroplasty in patients under the age of fifty: a five- to ten-year follow up. $J$ Arthroplasty 1998;13:485-91.

22. Kim YH, Kook HK, Kim JS. Total hip replacement with a cementless acetabular component and a cemented femoral component in patients younger than fifty years of age. J Bone Joint Surg [Am] 2002;84-A:770-4.

23. Amstutz HC, Antoniades JT, Le Duff MJ. Results of metal-on-metal hybrid hip resurfacing for Crowe type-I and II developmental dysplasia. J Bone Joint Surg [Am] 2007:89-A:339-46.

24. Little CP, Ruiz AL, Harding IJ, et al. Osteonecrosis in retrieved femoral heads after failed resurfacing arthroplasty of the hip. J Bone Joint Surg [Br] 2005;87-B:320-3.

25. Steffen RT, Smith SR, Urban JP, et al. The effect of hip resurfacing on oxygen concentration in the femoral head. J Bone Joint Surg [Br]2005;87-B:1468-74.

26. Murray DW, Little JP, Steffen RT, et al. Femoral neck fractures following resurfacing. Procs IMechE 2007:137-9.

27. Hing CB, Young DA, Dalziel RE, et al. Narrowing of the neck in resurfacing arthroplasty of the hip: a radiological study. J Bone Joint Surg [Br] 2007;89-B:1019-24. 